\title{
ADSORPTION OF USED TRANSFORMER OIL ON ACTIVATED CHARCOAL AND CHANGES IN THE CHEMICAL PROPERTIES
}

\section{M. Shivankar}

Deptt. Of chemistry, Dr. Ambedkar College, Deekshabhoomi, Nagpur.

E-Mail: vidyadharshivankar@gmail.com

\begin{abstract}
Transformer oil is generally used in electrical transformer. It contains higher hydrocarbons. In used transformer oil, physico-chemical parameters are changed. These parameter can be restored by the adsorption treatment on used transformer oil. There are changes in properties like kinematic viscosity, acidity, Sp.gravity, Diesel Index, pour point etc. These properties were studied after reclamation of used transformer oil.
\end{abstract}

Keywords: Physico-chemical properties, transformer oil, adsorption, Activated charcoal

\section{INTRODUCTION}

Transformer oil is thick petroleum product obtained in the refining industry. It contains the mixture of higher hydrocarbons [1]. Due to continuous use in transformer, the physico-chemical properties of the transformer oil are changed and thereafter oil gets deteriorated. After deterioration of oil and its continuous use, there is a possibility to damage the transformer [2].

The properties like kinematic viscosity, Pour point, sp. Gravity, are changes. Such deteriorated transformer oil can be purified or reclaimed by using certain adsorption treatment with suitable adsorbent [3]. After adsorption the properties of reclaimed oil are studied by international testing methods. After testing some properties, it can be concluded that whether used transformer oil should be reused again or not [4]. 


\section{EXPERIMENTAL}

Adsorption of used transformer oil was carried out in batch reactor. For this the reactor was filled with known quantity of used transformer oil. This reactor is placed on heating mental so that the adsorption can be carried out at different temperature. The round bottom flask can be used as a batch reactor where the adsorbent was treated with used transformer oil.

Stirrer was introduced in the batch reactor or round bottom flask in order to maintain the uniform mixing of adsorbent with used transformer oil. In this adsorption method activated charcoal was used as an adsorbent.

After adsorption, filtration was carried out and filtered oil was stored in different sample bottles.

Different physico-chemical properties were determined as per BIS specification standard.

\section{OBSERVATION TABLE}

\begin{tabular}{|l|l|l|l|}
\hline Sr.No. & Properties & $\begin{array}{l}\text { Without } \\
\text { adsorbent }\end{array}$ & After adsorption \\
\hline 1 & Sp.gravity (g/ml) & 0.9884 & 0.8014 \\
\hline 2 & Surface tension (d/cm) & 48.54 & 51.23 \\
\hline 3 & Diesel Index & 19.96 & 65.18 \\
\hline 4 & Kinematic viscosity (Cs) & 21.81 & 14.13 \\
\hline 5 & Pour point (deg. Cent.) & 4 & 2 \\
\hline
\end{tabular}




\section{RESULT AND DISCUSSION}

After adsorption of used transformer oil by adsorbent Activated charcoal, tremendous changes in some chemical properties were observed.

Sp.gravity of used transformer oil was decreased after adsorption. It means that transformer oil become lighter due to the removal of impurities.

Diesel Index shows increase after adsorption. This indicates thick transformer oil become thin and tries to acquire chemical properties of diesel by removing some higher hydrocarbons.

Kinematic viscosity decreases after adsorption, indicate oil become more viscous and purify to some extent by using activated charcoal as adsorbent.

Decrease in pour point values confirm some paraffin wax was removed.

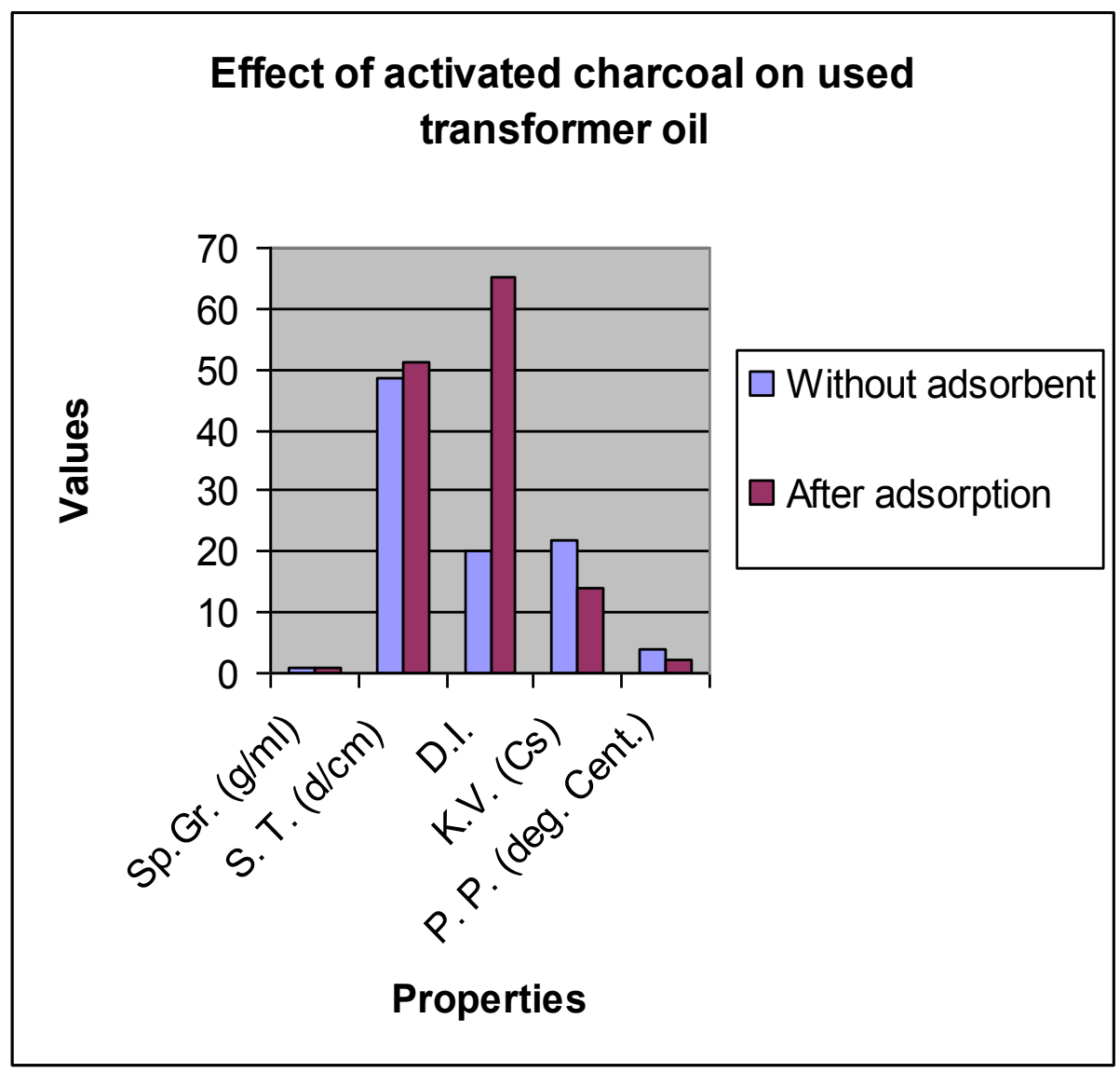




\section{CONCLUSION}

From the above discussion it concludes that used transformer oil get purified to some extent by adsorption method. Above observed physicochemical properties after purification compared with BIS specification. Quantity of used oil decreases during adsorption. It is eco-friendly and has green chemistry application. This saves a lot of expenditure by purifying waste transformer oil.

\section{REFERENCES}

A Guide to Transformer maintenance by S.D.Meyers.

National fire protection Association. Electrical Equipment maintenance (1977)

Billet, M. (1999). Institute of lubrication Pegomon Ltd.

London. P.P. $234-239$.

Harry, M.J. (2005). Standard handbook of Hazardous waste and disposal. 